\title{
2. Stories and Storytelling in the Era of Graphic Narrative
}

\author{
Jan Baetens
}

\section{Diversity and Inequality of Stories}

As claimed by Roland Barthes, one of the founding fathers of modern narratology, stories are universal and can be told in all media:

There are countless forms of narrative in the world. First of all, there is a prodigious variety of genres, each of which branches out into a variety of media, as if all substances could be relied upon to accommodate man's stories. [...] Moreover, in this infinite variety of forms, it is present at all times, in all places, in all societies [...] there is not, there has never been anywhere, any people without narrative. $(1975,237)$

However, if all stories are equal, some are more equal than others and, in some cases, the difference between stories - whether they are worth studying or not, prestigious or despised, heavily promoted or ignored, canonized or kept at the margins as mere entertainment - has to do with issues of medium and medium-specificity. Although a number of things have changed, words are still judged as being more suitable for storytelling than just images, which are typically suited to description and the representation of fixed objects - see the long posterity of Lessing's Laocoön (1776) and the still-raging debates on the respective qualities of the action-oriented verbal sequences and family resemblance between visual simultaneity and immobile subjects. Moreover, within the field of visual storytelling, imposed by the spread of mobile images or the combination of words and images in multiple panels and series, certain media and image types continue to face strong resistance, either because they are considered hybrid and therefore "impure" or because cultural gatekeepers define them as lowbrow, if not utterly vulgar. Once again, much has changed in this regard. It would be absurd to claim, for instance, that cinema is a less interesting or adequate medium than literature since it mixes words and images or because it is deeply rooted in the world of commerce and the culture industries (currently, we all accept that cinema has "remediated" literature [Bolter and Grusin 1999]). But these changes in status are far from complete. Think, for instance, of 
the continuing scorn of the photo novel (Baetens 2017), a medium that still suffers from its historical links with melodrama and patriarchal biases against women's and girls' magazines (Gibson 2015).

On the other hand, the universal character of storytelling and story structures does not mean that narrative is always seen through a positive lens. From an aesthetic and cultural-historical point of view, many modernist movements have criticized the normalizing and stultifying effects of narrative, allegedly harmful to all that Modernism should be about, namely the progressive disclosure of the material infrastructure of the medium - color and flatness in painting (Greenberg 1940), the productive play of the verbal signifier in literature (Ricardou 1978), or montage and projection in (analog) cinema (Krauss 2000), among other examples. From a social and political point of view, the use of storytelling techniques has been associated with manipulation and propaganda (Faye 1972; Salmon [2007] 2017). However, its problematic aspects also appear in the theoretical debates on the reduction of narrative methodologies to a mere toolbox, which is subject to all kinds of commercial uses and abuses (Baroni 2017). Once again, it is important to stress that most recent research has abandoned all extremist and one-sided refusals of storytelling as such. While Lev Manovich (2000) could still claim the supersession of narrative structures of classic, that is verbal culture, by the database logic of digital culture, Hayles (2007) rapidly defended a more ecumenical approach of narrative and nonnarrative as being inevitably and inextricably linked. In addition, an author such as Andrei Molotiu (2009), who has been instrumental in the foregrounding of abstraction in comics, has never denied the possibility of giving narrative meanings to apparently nonnarrative forms and structures. However, the resistance to storytelling - or at least toward certain forms thereof - cannot be reduced to twentieth-century Modernism. All historians of the (realistic) novel stress the initially poor reputation of this type of narrative, which was not seen in the beginning as a culturally legitimate challenger of older and often much less narrative types of literature (for a broad historical discussion of this debate, see Auerbach [1933] 2016).

It is against this double backdrop - that of the competition between forms and media of storytelling on the one hand and the not always unchallenged position of storytelling as an art form on the other - that I wish to address the role and place of "graphic narrative" in contemporary narrative. The stakes of such a discussion are not only intra-medial, that is aiming at highlighting the medium-specific features of the "graphic narrative" field, but also intermedial, that is comparative, as is the case with film studies. More specifically, the study of "graphic narrative" can strengthen and broaden a 
wide range of ongoing debates in film scholarship which, on the one hand, deal with the status of genre fiction (which is a very different type of fiction than what is meant by the concept of fiction when it is not customized with the help of a genre label), the medium-specific attitudes toward the global move toward digitization (which, in the field of "graphic narrative" discloses interesting forms of resistance), and, more generally, the place of narrative itself (which is far from being natural or self-evident in some of the cutting-edge types of "graphic narrative," where anti-narrative stances are less marginal than those in cinema).

\section{Graphic Narrative in the Expanded Field}

In recent discussions the notion of "graphic narrative" is no longer a term that refers to "vividly and visually explicit" narrative, which can be performed by purely verbal means as well, but an umbrella term that designates the narrative use of sequentially arranged photographs or drawings, often supported or enhanced by captions, speech bubbles, and other verbal elements (for practical reasons, I will focus here on a specific type of graphic narrative, i.e., that of comics and graphic novels). ${ }^{1}$ Today, graphic narrative in general, and comics and graphic novels in particular, have become ubiquitous, both in quantitative and qualitative terms. They are not only omnipresent (and commercially successful) but also increasingly accepted as a culturally valuable form of storytelling.

It is commonly assumed that the opening of literature and literary studies to comics and graphic novels is a typically postmodern phenomenon, which firstly has to do with the continuous hybridization of media and art forms (and since comics and graphic novels generally combine words and images, they are perfect candidates for this kind of hybridization) and, secondly, the progressive dismantling of the frontiers between high and low art (and the merger of literature, a traditional high art, and comics and graphic novels, a developing form of low art is an appropriate example of this tendency). Obviously, the impact of these evolutions cannot be denied. However, there is more at stake in the emergence of comics and graphic novels as literary forms, more precisely as acceptable forms of literary storytelling (i.e., stories one can buy in a regular bookshop, teach in high schools and colleges, take as the object of an academic publication, and, eventually, institutionalize as the core of new university programs and careers).

The vital reason for such success is not only the postmodern character of graphic narratives but also the fact that they represent an answer to a 


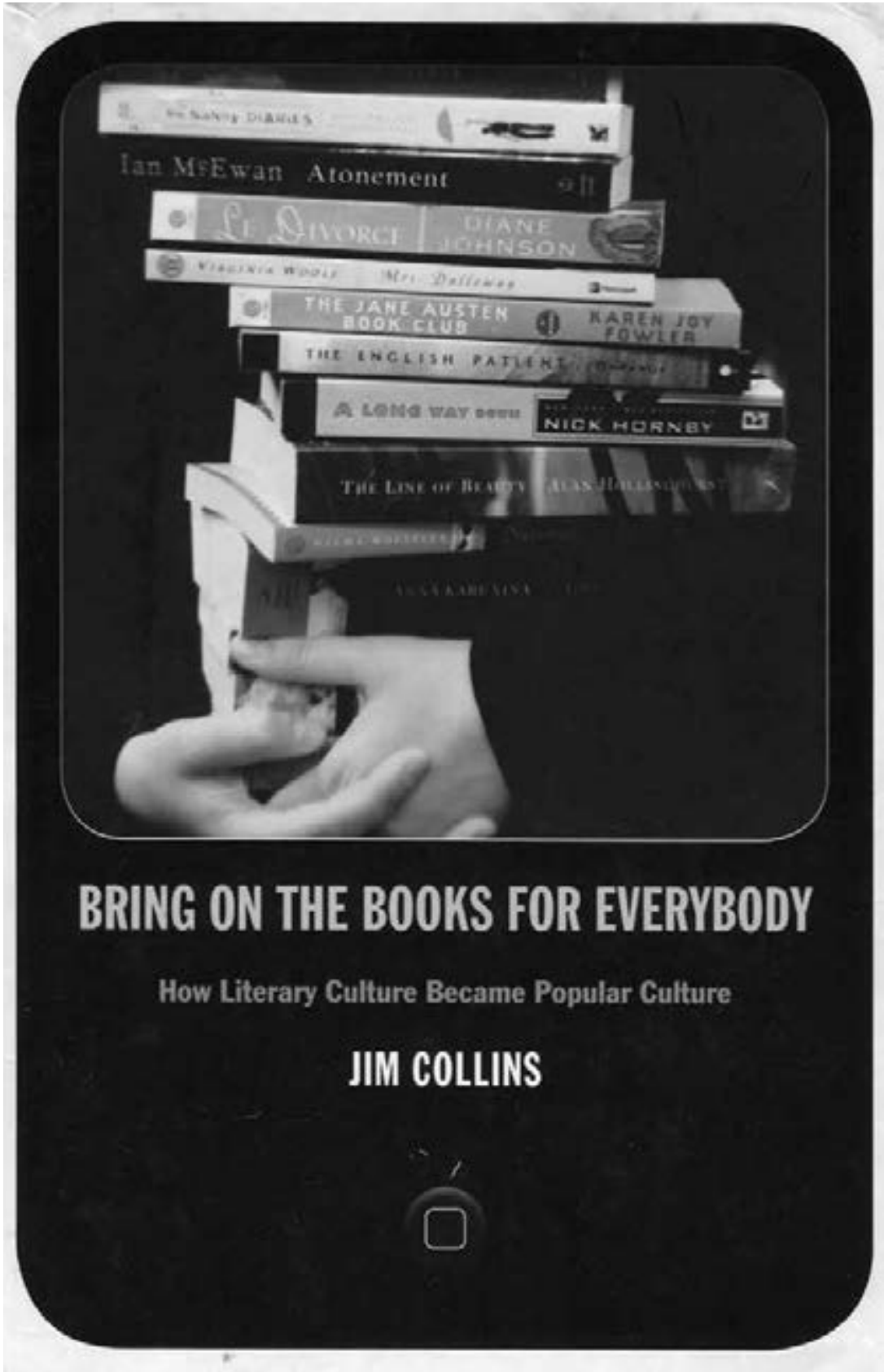

Fig. 2.1: Cover of Jim Collins, Bring on the Books for Everybody (2010). 
specific historical problem: that of the gradual vanishing of storytelling in more highbrow forms of literature around 1980 and thus the mismatch between supply and demand, that is between what literature was offering to the larger audience and the expectations of the latter which were no longer met by the former. In other words, if the public continued to look for models and examples that told readers how to shape their lives, how to behave in society in a responsible and satisfying way, and how to work on personal taste and individual development - all crucial incentives for the larger consumption of literary narratives - modern literature had become increasingly reluctant to cater to these needs, to which it preferred an esthetically more radical yet socially more narrow exploration of its own characteristics (Marx 2005). Jim Collins, a sharp observer of the social reactions to this shift, has described the effects of the gap between general readers and modern writers as well as between these readers and academically trained professional critics. Since the preferences of the latter no longer reflected those of the audience and its deep-rooted longing for self-cultivation and social interaction through cultural practices, new types of gatekeepers and collective involvement in reading appeared, as demonstrated by the tremendous success of Oprah Winfrey and other middlebrow tastemakers such as Martha Stewart who proved capable of offering, in a user-friendly way, what a liberal arts education, overspecialized and dramatically turned toward theoretical sophistry were no longer providing: affordable models and best practices for building a good life (Collins 2010).

Since the social need for "relevant," that is socially and personally "useful," storytelling is no longer supplied by certain forms of literature (in this case, contemporary literature, taking on board the high-modernist critique of narrative and its desire to turn realistic narrative into pure art), the public turns either to other forms of literary storytelling, regardless of the artistic value of its products (romance readers do not care about the lack of prestige of the genre) or to nonliterary forms, such as movies in the first place, and comics and graphic novels, which take the place that high art literary storytelling was no longer willing (or smart enough) to occupy around 1990. The rise of the graphic narrative as a literary form can therefore not be reduced to internal changes of the medium, as epitomized by the emergence of the "graphic novel" label during the 1980 os (with 1986 as a pivotal year, with the simultaneous appearance of the first installments of Frank Miller's Batman, The Dark Knight Returns and Moore and Gibbons,' Watchmen, both "recycled" as graphic novels one year later, and the first volume of Art Spiegelman's Maus, whose serialization had started in 1980). The graphic narrative's success outside the field of comics, where it first appeared in 


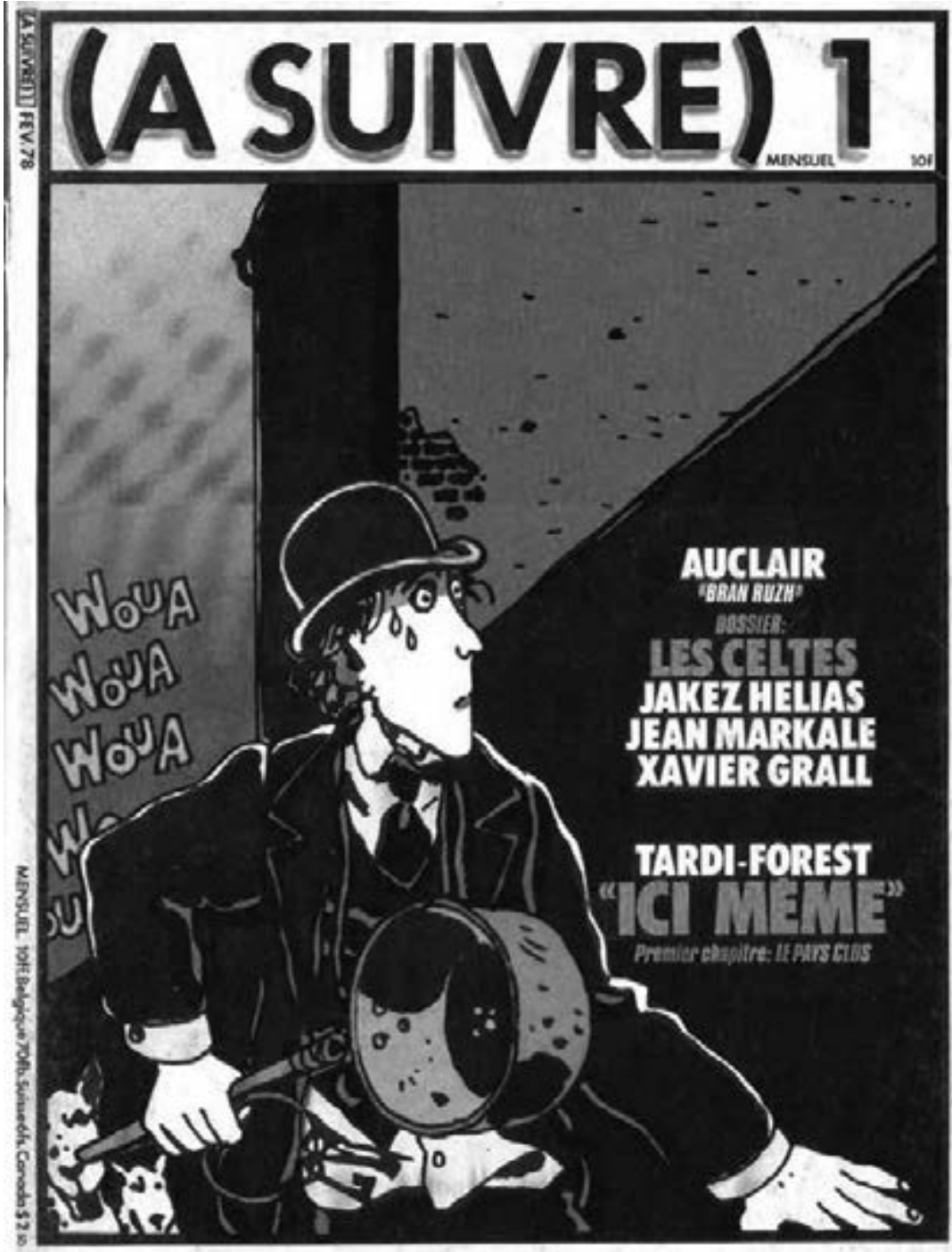

Fig.2.2: Cover of the first issue of (A Suivre).

the early nineteenth century, cannot be separated from a larger demand for storytelling in print. That (serious) comics really aimed at being read as a literary form, is a claim that is shared by all defenders of the graphic novel, such as Will Eisner, whose A Contract with God (1978) was explicitly framed and marketed as a serious fiction for readers who no longer had the time to read long novels, and Jean-Paul Mougin, the founding editor of A Suivre (1978-1997), whose opening manifesto in the first issue of the 
magazine foregrounded "l'irruption sauvage de la bande dessinée dans la littérature" (the bold entrance of literature into comics $[1978,3])$. Mougin militantly quoted as his major models the genre of the adventure novel and the work of R.L. Stevenson, that is, forms of literature that are dramatically narrative as well as highly popular but not necessarily highbrow.

The almost organic encounter between literature and graphic narrative can also help to explain the intriguing question that is raised by Bart Beaty in various publications (Beaty 2012; Beaty and Woo 2016): Why are comics ${ }^{2}$ a medium that, after all, gives more importance to the visual than the verbal, considered literature rather than a new form of narrative visual art? Beaty's main argument with the regard to the mutual misunderstandings, if not open hostility, between the world of comics and that of art, is of course a key element in the debate (Frey and Baetens 2018). However, it is no less important to stress the warm welcome given to graphic narratives in the field of literature, which partially solves the deep status issues with which comics and graphic novels were, and still are, struggling.

The graphic narrative case is therefore an excellent illustration of the cultural and historical embeddedness of any storytelling practice. Stories may be universal and ubiquitous, but their diverse forms are not equal: their social status is different, as is the degree of acceptation of storytelling in different fields. Moreover, these forms compete with one another at moments of change, which also generate internal changes within each form. In the next paragraph, I will focus on the most crucial changes in the domain of graphic narrative, namely the split or tension between comics and graphic novels.

\section{Graphic Storytelling and Genre Issues}

The rapid institutionalization of graphic narrative as a fully fledged literary narrative form has had many consequences for the treatment of story and storytelling. It produced a remarkable debate on the internal unity of the field, which opposed two nearly incompatible stances. On the one hand, the promoters of traditional comics refused to fully acknowledge the specificity and autonomous position of a new trend in graphic storytelling, namely the graphic novel, a type of comic that its defenders considered, quite on the contrary, as something completely different from traditional comics.

The distinction between these two visions is not purely technical. True, the distinction between both types seems rather easy to establish: comics are for kids, while graphic novels target an adult audience; comics are most 
often printed in comic books and sold in newsstands, while graphic novels are available in real bookshops; comics are generally made collectively by teams of artists hired to closely follow an editorial line and style, while graphic novels are mostly made by individual authors, who often position themselves as "auteurs" (in the technical sense coined by French film theory) and who are in charge of both the writing and drawing of the story; comics are almost always serial stories, which continue as long as the public is eager to buy them, while graphic novels tend to be stand-alones, which require the author to reinvent him- or herself at each new publication; comics are cultural-industrial products which have to have a recognizable house style and content, while graphic novels are supposed to experiment with style as well as content; comics have to obey a strict publication format (size, number of pages, serialization rhythm), while graphic novels may have various formats and publication types, and so on. Yet, in spite of these blatant technical and material differences, the distinction between comics and graphic novels remains open to debate, not only with regard to drawing techniques and publication formats but also at the level of storytelling practices. First of all, for socio-political reasons, the appearance of the graphic novel, which is often perceived as a quality label given to separate "good" from "bad" comics, is considered a vicious and politically suspect maneuver to exclude comics from the more prestigious domains of literature or art, if not as an even more deceptive operation to save these domains from what is key to low-art, namely the vitality and vulgarity of mass culture as well as its direct relationship with actualities and socio-political issues. According to these critics, the graphic novel is less an attempt to upgrade comics than an exercise in muzzling what makes popular culture so unacceptable to high art and elite culture (Pizzino 2016). According to those who maintain the unity of the field, many comics are actually doing what graphic novels claim to do, whereas many graphic novels fail to maintain the socio-political relevance of much lowbrow culture.

Yet the socio-political dimension of this debate cannot be severed from a properly theoretical and aesthetical debate on the question of storytelling. As a matter of fact, the conflict between comics and graphic novels reproduces, in more ways than one, the art-historical and literary debate between traditional works of art, where storytelling remains the key feature of any creation and consumption, and modernist or modernizing art, where the focus shifts from the narrative and figurative dimension to something else (pure form, the documentary, political commitment, for example). More precisely, the "upscale" resistance to "vulgar" narrative (here, I am rephrasing the terminology of those who oppose the cultural and aesthetic 
claims of the graphic novel within the larger field of the graphic narrative) relies on two major mechanisms.

Firstly, many graphic novels prefer to highlight what makes them so different from comics by rejecting what is often considered to be the basic feature of popular storytelling: target-oriented plots, high-speed action, heroic figures, thematic exaggerations, formulaic style, and all kinds of visual and narrative standardization. Graphic novels, on the other hand, tend to focus on anti-heroes; emphasize the absence of action to the point of utter boredom; and systematically underscore repetition, boredom, and uneventfulness, both thematically and visually (Schneider 2016). In their most extreme form, these graphic novels turn into "abstract" works, which no longer have any visible presence of action, setting or character (Molotiu 2009). This anti-narrative stance clearly echoes the typically modernist trend toward replacing the traditionally dominant pole of temporal structures by the newly hegemonic aspect of visuality within literature (Frank [1945] 1991; Mitchell 1980).

Secondly, the perhaps overstated difference between (generally overtly) narrative comics and (sometimes covertly) anti-narrative graphic novels, also takes the more nuanced, yet culturally no less significant form, of the difference between genre fiction and fiction in general. Whereas most comics stick closely to genre conventions - and thus belong to the field of genre fiction - graphic novels try to avoid all genres that fall prey to this kind of thematic and stylistic streamlining. Graphic novels either "deconstruct" existing formulaic genres, such as most exemplarily the "funny animals" genre reused by Art Spiegelman in Maus, or they explore new genres that were never within reach of comics, such as the autobiography (preferably linked with the issues of trauma and disability, often with a strong class, sex and gender dimension), both in its direct and auto-fictional variants, on the one hand, and the documentary (as seen in graphic journalism and graphic biographies, for instance) on the other. The success of these new genre experiments, most of which are perfectly compatible with the tendency toward decreased narrativity, is such that critical voices have underlined the formulaic turn of much of these nonnarrative antinarratives:

Two ideas that have poisoned a cross section of contemporary writing in general have also, to some extent, seeped into comics. One is the sentimental memoir (a first-person story that explains why the author is in the right and why his or her pain and sadness are worse than yours). The other is the toxic maxim "write what you know": the idea that, even in fiction, an author's imagination has to be directly limited by his or her 
personal experience. The rise of autobiographical or semi-autobiographical comic books brought these ideas into play in comics and opened up the question as to how cartoonists might best represent their own experience. (Wolk 2007, 203)

Therefore, storytelling is both the solution and the problem with regard to the transition from comics to graphic novels in the field of graphic narrative. On the one hand, the refusal of old genres of comic storytelling (all typically genre fiction formats: adventure, fantasy, science-fiction, horror) as well as the more general attempt to escape the constraints of action-driven storytelling, help the graphic novel bring to the fore uncharted territories, subjects, themes, and characters. On the other hand, this shift is not deprived of new stereotypes, some of which, as Wolk's quotation cunningly suggests, are dictated by the artistic superego of the newly emerged pseudoliterary form. In an attempt to be taken seriously as real literature, graphic novels copy the most directly available writing techniques - those taught in countless creative writing classes - and therefore even more easily fall prey to all kinds of clichés "real" literature would try to escape.

The combination of new ambitions and old forms also becomes very clear in the graphic novel's attitude toward a fundamental technological feature of contemporary storytelling, namely digitization.

\section{New Stories, Old Media}

Seen as a narrative form, rather than as a form of (virtually nonnarrative) visual art, graphic narrative is also part of a specific cultural industry, particularly that of the publishing business. It is, therefore, logical that it follows the major trends of this business, which can be summarized along three lines, and which rapidly prove to be quite close to what can be observed in the film industry. Firstly, there is the increasing commercialization of publishing, where the traditional role of the publisher as cultural gatekeeper is taken over by the financial interests of noncultural stakeholders that claim a high return on investment (Thompson 2012; Schiffrin 2000). As a result of this evolution, the split between commercial trade publishing and old-school independent publishing has become abyssal (however, even commercial trade publishing is becoming increasingly dependent on other players in the field, such as the distribution system - think of Amazon, the largest bookseller in the world). Secondly, there is the absorption of trade publishing in multimedia consortia and the necessity to develop new content - or to 


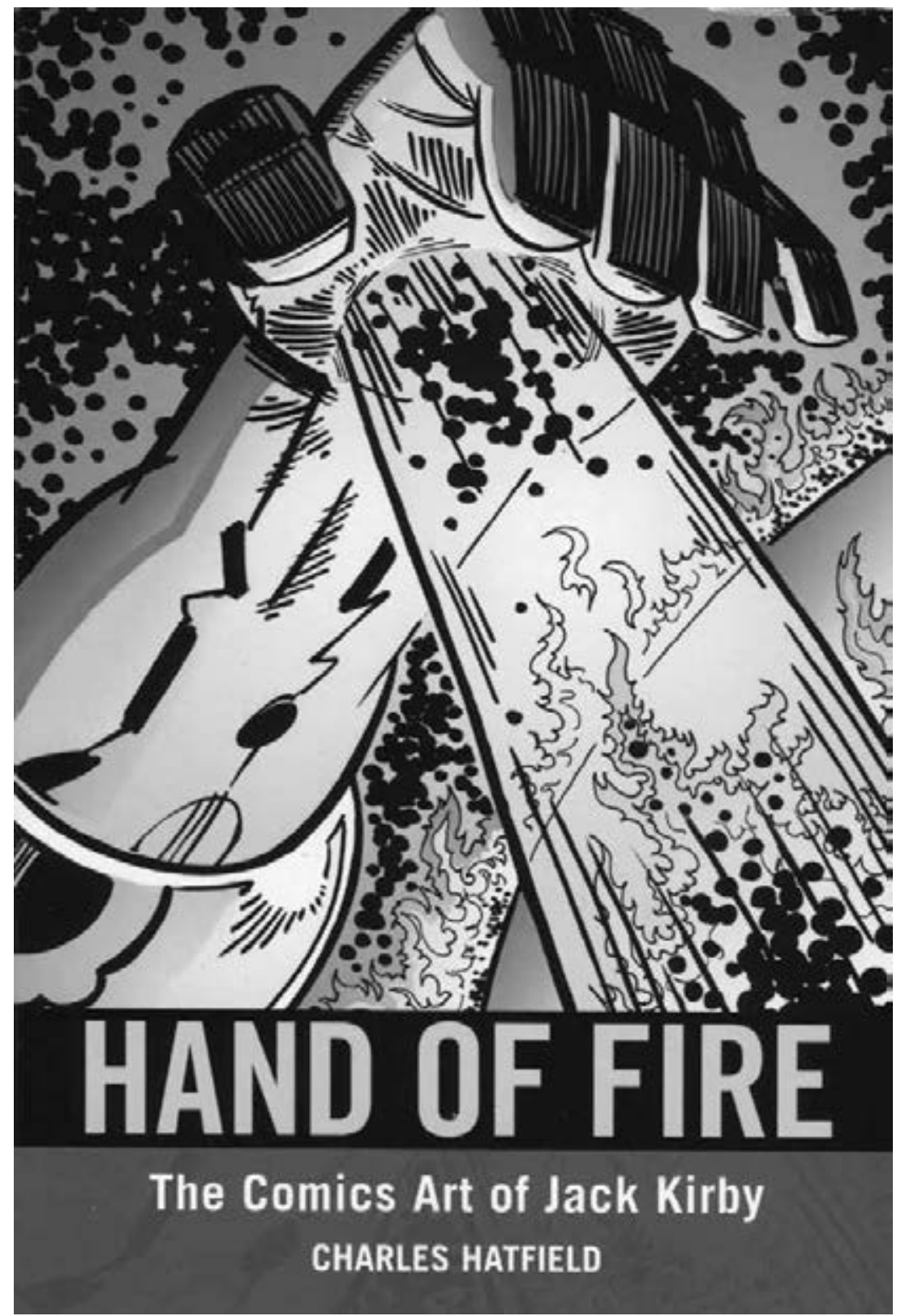

Fig. 2.3: Cover of Charles Hatfield, Hand of Fire (2011).

redesign old content - in various media and on different platforms in order to achieve supplementary benefits (Brouillette 2014; Murray 2013). In its simplest form, this tendency translates into the commercial obligation to 
adapt a work in other media (and, thus, to sell and resell as many times as possible the copyrights related to it). Mass culture is not only intermedial; it is also a type of culture that inevitably migrates from one medium to another (often with amazing and exciting results). In its more recent and comprehensive form, this tendency toward medial variation takes the form of transmedia storytelling, a term that refers to the systematic dispersion of fiction "across multiple delivery channels for the purpose of creating a unified and coordinated entertainment experience. Ideally, each medium makes its own unique contribution to the unfolding of the story" (Jenkins 2007). Thirdly, the entire publishing industry has taken a digital turn that radically dissociates what was inextricably linked in the traditional book format: content and host medium (Thompson 2012).

Graphic narrative illustrates these three tendencies very well. Moreover, each of them powerfully reflects the tension - indeed so well-known in the film industry, where the financial stakes are incomparably much higher between the cultural-industrial strand exemplified not only by many comics, but also by some graphic novels, and the more independent, "do it yourself" approach of many graphic novels and some comics. It would be absurd to believe that there is a seamless match between comics and the trade publishing industry - currently DC (Warner Bros/Time Warner) and Marvel (Disney) - on the one hand and graphic novels and independent or self-publishing ${ }^{3}$ - in the Anglo-Saxon field mainly Fantagraphics (Seattle) and Drawn and Quarterly (Montreal) - on the other. Everybody knows the stereotypical antagonism between the stereotyped vision of the sweatshop industry of the comic book in its Golden and Silver Age, as famously described by the artists themselves (Eisner [1985] 2008) and the slightly romanticized reinterpretation of this industry by their novelist-historians (Chabon 2000). However, the Taylorized production line of these works was far from stealing creative freedom and, to a certain degree, managerial control from those whom David Hesmondalgh (2002) called "symbol creators" (for an example in the comics field, see Hatfield 2011; various examples on film and television are given by Hesmondhalgh).

More generally speaking, the comics industry has repeatedly been uncritically opposed to the alleged complete freedom of authors in the graphic novel field, where commercial constraints are no less present. If the comix underground movement of the late 1960 s can be seen as the forerunner of the (American) graphic novel, one should not forget that the same authors are now publishing with major companies such as Pantheon, a Knopf Doubleday imprint. Similar observations could be made on the tendency toward adaptation and transmedialization, which have become almost default options in the comics industry, but which remain rather exceptional 
in the graphic novel field. However, it would be a mistake to think that this evolution is new or even recent in the comics field (for an example of comics marketing and cross-medial adaptation and appropriation in the nineteenth century, see Sabin 2003; for an overview of the interaction between comics and cinema, see among many others, Boillat 2010) or that independent artists systematically refrain from adaptations or even going transmedial. While it is true that most authors certainly do refrain from it (it suffices to think of Spiegelman's repeated refusal to authorize a film version of Maus), typically independent authors such as Robert Crumb or Daniel Clowes are not afraid of collaborating with Hollywood. It should also be stressed that the tendency toward intermedialization (i.e., the combination of several media within a single work) is much stronger in the graphic novel industry than in the comics field. The combination and hybridization of photography and drawing is incomparably more frequently used in graphic novels than in comics (Pedri 2017). It is not absurd or exaggerated to suppose that there may be a link with the relative absence of cross-medial adaptations. Since graphic novels are less frequently adapted for the screen, the dialogue with other types of media - an inescapable feature of all contemporary graphic narrative - is not "outsourced" to the film industry, but included in the creative work itself.

However, the most interesting tensions and differences can be observed at the level of digitization, which continues to be strongly rejected by most graphic novelists, whereas nowadays, the comics industry is offering most of its products in electronic formats as well. The resistance to digitization is not only due to nostalgia and the fetishism of paper and ink (for the author) and the touch and feel of the book (for the reader), but also the actual making, printing, distributing, and consuming of graphic narratives, which entails countless digital steps and aspects. Neither is it due to the less satisfying results of some digital comics, which often poorly replicate on-screen the visual affordances of the page and the book, nor to the relative slowness of the emergence of digitally born comics (Crucifix and Dozo 2018). Instead, the most fundamental obstacle is the everlasting influence of a proper narrative mechanism, namely the idea that storytelling on-screen is in the very first place a matter of "clicking through" from screen to screen. Most influentially voiced by Scott McCloud (2000), this idea was probably inspired by the 1990s hegemony of the concept of hypertext fiction; that is, a genre of electronic literature, characterized by the use of hypertext links that provide a new context for nonlinearity in literature and reader interaction. At the moment of the first systematic attempts to establish digital graphic narratives, hypertext fiction was the new Promised Land and its prestige definitely influenced the way in which creators imagined 
the new digital graphic narratives to come. Not unlike hypertext fiction, which has almost disappeared from the field of literary creation, the "clicking through" mechanism proved to be a dead end, and one can easily understand why. The foregrounding of the panel-to-panel (or, in this case, the screen-to-screen) transition as the driving force of narrative progress tends to exclusively highlight the linear aspects of graphic storytelling and minimize the second great dimension of graphic storytelling, namely the exploration of the simultaneous presence of images and visual elements within a certain frame (which, in the case of graphic storytelling, is generally a multiframe: one-panel pages are exceptional, and even then one has to take into account the echoes between the two pages of the spread). In comics, the importance of linear panel-to-panel transition is often much stronger than that of the nonlinear copresence of all elements on the page or the double spread. It is not uncommon for graphic novels to work the other way round, foregrounding the singularities of the mosaic-page rather than the features of its single panels or images. Hence, the differences between both types of storytelling - the one that focuses on linear unfolding and the other that underlines the simultaneous presence of different visual items or units - in a digital environment that still tries to prioritize the "clicking through" button and which, for that reason, seems more open to comics' linearity than the combination of linearity and simultaneity typical of the graphic novel. One can, however, presume that things will change very rapidly once graphic narrators have superseded the "clicking through" default option.

To conclude, I would like to stress once again that graphic narrative, which has now become a major player in the field of narrative in print, is not a phenomenon that can be explained in literary or artistic terms alone. As suggested by the past, present, and future of this cultural form, which has emerged as comics in the margins of the cultural system before being reshaped alongside the growing opposition between comics and graphic novels once it started participating in the field of culturally legitimate storytelling, in analog as well as in digital forms, graphic storytelling is a multilayered process in which technical, aesthetic, historical, and ideological dimensions are inextricably intertwined. The most interesting conclusion that can be drawn from the study on graphic narrative is that a "global," that is, a crossmedial and linear approach to stories and storytelling, is highly problematic. The study of graphic storytelling suggests that stories do not always evolve in the same direction in various media and genres and that even without each medium and genre, it makes sense to pay attention to individual cases, local contexts, and certain forms of anachronisms. Furthermore, it is important to note that this is a lesson that may apply to film studies as well. It is true 
that graphic narrative is not a field that has the same cultural and economic importance as cinema, but the diversity of the field and the rapid, though not always sustainable, changes that characterize it can serve as a modest but useful echo chamber for ideas and hypotheses that are tested in the broader field of film studies and storytelling in general. From this point of view, graphic storytelling deserves to be studied as a key domain in the larger field of cultural narratology (with film studies as a specific subfield).

\section{Notes}

1. The term "graphic narrative" may be somewhat misleading for non-specialists, but it is becoming increasingly popular as an alternative to terms such as "comics" and "graphic novels," which cover more specialized forms of the general field of graphic literature (Baetens and Frey 2015). There are, of course, many other forms of visual narrative such as, for instance, narrative illustrations, as in the multimodal novel (Hallet 2009), not to mention the various kinds of narrative that rely on mobile images. However, in what follows, "graphic narrative" will refer exclusively to works in print in which a story unfolds with the help of drawings, regardless of whether or not these drawings are accompanied by verbal elements. The emphasis on drawings, rather than on pictures, is both pragmatically and theoretically motivated. In spite of the many convergences between these two forms of graphic narrative, both subtypes are also characterized by many differences. Similar remarks apply to the hybridized forms of drawn and photographic narratives, which tend to raise very specific questions that are not necessarily of vital importance for the current discussion.

2. As in his other publications, Beaty is focusing less on graphic novels than on comics, an attitude that reflects a polemic to be discussed below, but which does not impact the discussion on literature versus visual arts too much.

3. A highly nuanced approach is all the more necessary since self-publishing is being increasingly promoted by major distributors such as Amazon, who uses it as a tool to weaken the position of traditional publishers.

\section{References and Further Reading}

Auerbach, Erich. 2016 [1933]. "Romanticism and Realism." In Selected Essays of Erich Auerbach: Time History, and Literature, edited by James I. Porter, translated by Jane O. Newman, 144-156. Princeton: Princeton University Press.

Baetens, Jan. 2017. Pour le roman-photo (expanded ed.). Brussels: Les Impressions Nouvelles. Baetens, Jan, and Hugo Frey. 2015. The Graphic Novel: An Introduction. New York: Cambridge University Press. 
Baroni, Raphaël. 2017. "L'empire de la narratologie contemporaine, ses défis et ses faiblesses." Questions de communication 30: 219-239.

Barthes, Roland. 1975 [1966]. “An Introduction to the Structural Analysis of Narrative." Translated by Lionel Duisit. New Literary History 6, no. 2 (Winter): 237-272.

Beaty, Bart. 2012. Comics Versus Art. Toronto: Toronto University Press.

Beaty, Bart, and Benjamin Woo. 2016. The Greatest Comic Book of All Time: Symbolic Capital and the Field of American Comic Books. New York: Palgrave.

Boillat, Alain. 2010. Les Cases à l'écran. Bande dessinée et cinéma en dialogue. Genève: Georg.

Bolter, Jay David, and Richard Grusin. 1999. Remediation: Understanding New Media. Cambridge: MIT Press.

Brouillette, Sarah. 2014. Literature and the Creative Economy. Stanford: Stanford University Press. Chabon, Michael. 2000. The Amazing Adventures of Kavalier and Clay. New York: Randhom.

Collins, Jim. 2010. Bring on the Books for Everybody: How Literary Culture Became Popular Culture. Durham, NC: Duke University Press.

Crucifix, Benoît, and Björn-Olav Dozo. 2018. "E-Graphic Novels." In The Cambridge History of the Graphic Novel (forthcoming), edited by Jan Baetens, Hugo Frey, and Steve Tabachnick. New York: Cambridge University Press.

Eisner, Will. 2008 [1985]. The Dreamer. New York: Norton.

Faye, Jean-Pierre. 1972. Théorie du récit, Introduction aux “langages totalitaires", La raison critique de l'économie narrative. Paris: Hermann.

Frank, Joseph. 1991 [1945]. The Idea of Spatial Form. New Brunswick: Rutgers University Press.

Frey, Hugo, and Jan Baetens. 2018. "Comics Culture and Roy Lichtenstein Revisited: Analyzing a Forgotten 'Feedback Loop.'” Art History (forthcoming).

Gibson, Mel. 2015. Remembered Reading: Memory, Comics and Post-War Constructions of British Girlhood. Leuven: Leuven University Press.

Greenberg, Clement. 1940. “Towards a Newer Laocoon." Partisan Review 7, no. 4 (July-August): 296-310.

Hallet, Wolfgang. 2009. "The Multimodal Novel: The Integration of Modes and Media in Novelistic Narration." In Narratology in the Age of Cross-Disciplinary Narrative Research, edited by Fotis Jannidis, Matías Martínez, John Pier, and Wolf Schmid, 129-153. New York: Walter de Gruyter.

Hatfield, Charles. 2011. Hand of Fire: The Comics Art ofJack Kirby. Jackson: The University Press of Mississippi.

Hayles, N. Katherine. 2007. "Narrative and Database: Natural Symbionts." PMLA 122, no. 5 (October): 1603-16o8.

Hesmondhalgh, David. 2002. The Cultural Industries. London: Sage.

Jenkins, Henry. 2007. "Transmedia Storytelling 101." Henry Jenkins. Confessions of an Aca-Fan (blog), March 21, 2007. Accessed November 1, 2017. http://henryjenkins.org/blog/2007/03/ transmedia_storytelling_101.html.

Krauss, Rosalind. 2000. "A Voyage on the North Sea": Art in the Age of the Post-Medium Condition. London: Thames and Hudson.

Lessing, G.E. 1984 [1766]. Laocoön: An Essay on the Limits of Poetry and Painting. Translated by E.A. McCormick. Baltimore: Johns Hopkins University Press.

Manovich, Lev. 200o. The Language of New Media. Cambridge: MIT Press.

Marx, William. 2005. L'Adieu à la littérature. Histoire d'une dévalorisation, XVIIIe-XXe siècle. Paris: Minuit.

McCloud, Scott. 200o. Reinventing Comics: How Imagination and Technology Are Revolutionizing an Art Form. New York: Random House. 
Mitchell, W.J.T. 1980. "Spatial Form in Literature: Toward a General Theory." Critical Inquiry 6, no. 3 (Spring): $539-567$.

Molotiu, Andrei. 2009. Abstract Comics: The Anthology. Seattle: Fantagraphics.

Mougin, Jean-Paul. 1978. "Introduction" (untitled). A Suivre, no. 1: 3.

Murray, Simone. 2013. The Adaptation Industry: The Cultural Economy of Contemporary Literary Adaptation. London: Routledge.

Pedri, Nancy, ed. 2017. "Mixing Visual Media in Comics." Special issue of ImageText 9, no. 2. http://www.english.ufl.edu/imagetext/.

Pizzino, Christopher. 2016. Arresting Development. Comics at the Boundaries of Literature. Austin: Texas University Press.

Ricardou, Jean. 1978. Nouveaux problèmes du roman. Paris: Seuil.

Sabin, Roger. 2003. "Ally Sloper: The First Comics Superstar?" Image (\&) Narrative 7 (October). http://www.imageandnarrative.be/inarchive/graphicnovel/rogersabin.htm.

Salmon, Christian. 2017 [2007]. Storytelling:Bewitching the Modern Mind. Translated by David Macey. London: Verso.

Schiffrin, André. 200o. The Business of Books: How the International Conglomerates Took Over Publishing and Changed the Way We Read. London: Verso.

Schneider, Greice. 2016. What Happens When Nothing Happens: Boredom and Everyday Life in Contemporary Comics. Leuven: Leuven University Press.

Thompson, John B. 2012. Merchants of Culture: The Publishing Business in the Twenty-First Century. London: Polity Press.

Wolk, Douglas. 2007. Reading Comics: How Graphic Novels Work and What They Mean. New York: Da Capo Press. 
